\title{
A machine learning model to predict death outcome in severe COVID-19 patients
}

\section{Qiao Yang}

The 941st Hospital of the PLA Joint Logistic Support Force

Jixi Li

Xinqiao Hospital

Zhijia Zhang

Xinqiao Hospital

Xiaocheng Wu

Xinqiao Hospital

Tongquan Liao

Xinqiao Hospital

Shiyong Yu

Xinqiao Hospital

Zaichun You

Army Medical University

Xianhua Hou

Southwest Hospital, Army Medical University

Jun Ye

Southwest Hospital, Army Medical University

Gang Liu

Xinqiao Hospital

Siyuan $\mathrm{Ma}$

State Key Laboratory of Trauma, Burns and Combined Injury

\section{Ganfeng Xie}

Southwest Hospital, Army Medical University

Yi Zhou

Xinqiao Hospital

\section{Mengxia Li}

Cancer Center囚Army Medical Center

Meihui Wu

Army Medical Center

Yimei Feng

Xinqiao Hospital

\section{Weili Wang}

Kidney Center of PLA, Army Medical University

\section{Lufeng Li}

Southwest Hospital, Army Medical University

\section{Dongjing Xie}

Xinqiao Hospital

Yunhui Hu

Southwest Hospital, Army Medical University

Xi Liu

Army Medical University

Bin Wang 
Xinqiao Hospital

\section{Songtao Zhao}

Southwest Hospital, Army Medical University

Li Li

Army Medical Center

Chunmei Luo

Xinqiao Hospital

Tang Tang

Xinqiao Hospital

Hongmei Wu

Xinqiao Hospital

Tianyu Hu

Xinqiao Hospital

Guangrong Yang

Xinqiao Hospital

Bangyu Luo

Xinqiao Hospital

\section{Lingchen $\mathbf{L i}$}

Xinqiao Hospital

\section{Xiu Yang}

Xinqiao Hospital

Qi Li

Xinqiao Hospital

\section{Zhi Xu}

Xinqiao Hospital

\section{Hao Wu}

Xinqiao Hospital

Jianguo Sun ( $\nabla$ sunjg09@aliyun.com )

Xinqiao Hospital

\section{Research Article}

Keywords: COVID-19, machine learning model, decision tree, LDH, NLR, CRP

Posted Date: March 19th, 2021

DOl: https://doi.org/10.21203/rs.3.rs-96621/v2

License: (c) (1) This work is licensed under a Creative Commons Attribution 4.0 International License. Read Full License

Version of Record: A version of this preprint was published at BMC Infectious Diseases on August 9th, 2021. See the published version at https://doi.org/10.1186/s12879-021-06478-w. 


\section{Abstract}

Background

The novel coronavirus disease 2019 (COVID-19) spreads rapidly among people and causes a global pandemic. It is of great clinical significance to identify COVID-19 patients with high risk of death.

\section{Results}

Of the 2,169 COVID-19 patients, the median age was 61 years and male patients accounted for $48 \%$. A total of 646 patients were diagnosed with severe illness, and 75 patients died. Obvious differences in demographics, clinical characteristics and laboratory examinations were found between survivors and non-survivors. A decision tree classifier, including three biomarkers, neutrophil-tolymphocyte ratio, C-reactive protein and lactic dehydrogenase, was developed to predict death outcome in severe patients. This model performed well both in train dataset and test dataset. The accuracy of this model was 0.98 and 0.98 , respectively.

\section{Conclusion}

The machine learning model was robust and effective in predicting the death outcome in severe COVID-19 patients.

\section{Background}

The novel coronavirus disease 2019 (COVID-19) has been a global pandemic. The most common symptoms of COVID-19 patients were fever, followed by dry cough, fatigue, dyspnea, etc[1, 2]. A small piece of patients had digestive symptoms, such as nausea, vomiting and diarrhoea[3, 4]. A study from the Chinese Center for Disease Control and Prevention reported that about 81\% COVID-19 patients were considered as mild, and the proportion of severe and critical patients was $14 \%$ and $5 \%$, respectively[5]. The mortality in overall population was $3.2 \%$, but it increased to $49 \%$ in critical population[5]. Hence, how to use effective biomarkers to identify patients with poor clinical outcomes have caused extensive concern.

COVID-19 patients with comorbidities were considered to be prone to having poor clinical outcomes. A study reported that COVID-19 patients with chronic obstructive pulmonary disease, diabetes, hypertension and malignancy had a higher risk of admission to an intensive care unit (ICU), invasive ventilation or death[6]. Another study demonstrated that the risk factors included older age, high Sequential Organ Failure Assessment score, and higher D-dimer expression on admission[7]. To help physicians identify potential patients with critical illness, Liang and colleagues developed a risk score model based on ten characteristics of COVID-19 patients on admission to calculate the probability of developing critical illness[3].

It is of great clinical significance to identify COVID-19 patients with high risk of death. In this study, we aimed to develop a machine learning model to distinguish COVID-19 patients with high risk of death from those without.

\section{Methods}

\section{Data sources}

A total of 2,169 adult patients (aged $\geq 18$ years) were enrolled from Wuhan, China between February 10th and April 15th, 2020. All patients were confirmed with COVID-19 infection by real-time reverse-transcription polymerase-chain-reaction (RT-PCR) assay. In addition, medical records, including demographics, clinical characteristics and laboratory examinations on admission of all patients were collected. This study was approved by the Ethics Committee of the Taikang Hospital (TKTJLL-007), and performed in accordance with the Declaration of Helsinki. The Ethics Committee of the Taikang Hospital waived the need for informed consent of each patients. This study was registered in the Clinical Trials Register (NCT04347369, https://clinicaltrials.gov/).

\section{Study design}

First of all, we performed a difference analysis of medical records between severe group and non-severe group. All the patients meeting the severity diagnosis criteria during hospitalization were assigned into the severe group. We defined disease severity according to the Seventh Revised Trial Version of the COVID-19 Diagnosis and Treatment Guidance (2020) of China[8]. Next, we performed difference analyses of medical records between survivors and non-survivors. The definition of survivors was patients who were discharged from hospital or still in hospital at the end of study. Last, we developed a decision tree classifier to identify risk factors for death outcome. 


\section{Statistical analysis}

Continuous variables were described as median and interquartile range (IQR) and compared by the Mann-Whitney U test. Categorical variables were represented as frequencies and compared by Pearson's $X^{2}$ test. All statistical analyses were performed and the decision tree classifier was developed using R software (version 3.5.2). The following R packages were used: CBCgrps, rpart, rpart.plot and pROC. A two-sided $P$ value $<0.05$ was considered statistically significant.

\section{Results}

Of the 2,169 COVID-19 patients confirmed by RT-PCR, the median age was 61 years (IQR, 50-70; range, 18-100 years). Male patients accounted for $48 \%$ (1036 cases) and female patients $52 \%$ (1133 cases). Approximately $8 \%$ of patients (184 cases) had smoking history. On admission, $117(5 \%)$ patients had high body temperature, 270 (12\%) had low oxygen saturation, $359(17 \%)$ had abnormal heart rates and 596 had faster respiratory rates. In total, 1134 (52\%) patients had at least one comorbidity, and the common comorbidities were hypertension, diabetes and coronary heart disease. In addition, 728 (34\%) patients had one system symptom, 1130 (52\%) patients had two systems symptoms and $218(10 \%)$ patients had three or more systems symptoms. The most common systems symptoms were respiratory symptoms, systemic symptoms and digestive symptoms (Table 1).

A total of 646 (29.8\%) patients were diagnosed with severe illness during hospitalization. Compared to non-severe group, severe group had a significantly higher median age ( 68 vs. 58 years, $p<0.001)$ and a higher proportion of male patients. On admission, a higher proportion of high body temperature, low oxygen saturation, abnormal heart rate and faster respiratory rate were found in severe group. Moreover, patients in severe group had a higher proportion of comorbidities and symptoms. No difference was found in the smoking history (Table 1). When comparing laboratory examinations between the two groups, we found that severe group had a significantly higher white blood cell (WBC) count, neutrophil count, neutrophil-to-lymphocyte ratio (NLR), and C-reactive protein (CRP), lactic dehydrogenase (LDH), interleukin-6 (IL-6), procalcitonin and D-dimer levels, but lower lymphocyte count, eosinophilia count, basophilia count, red blood cell (RBC) count, hemoglobin and platelet count. No difference was found in monocyte count (Table 1).

Until April 15th, 2020, 75 patients were dead. Differences in demographics and clinical characteristics between survivors and nonsurvivors were similar to the differences between severe and non-severe groups. By laboratory examinations comparison, a much higher WBC count, neutrophil count, NLR, and higher CRP, LDH, IL-6, procalcitonin and D-dimer levels were found in non-survivors (Table 2). RBC count and hemoglobin level showed no difference between the two groups. Other laboratory indexes were lower in non-survivors (Table 2).

To explore crucial predictive biomarkers of disease mortality in severe patients, we used a machine learning model, decision tree, to identify related biomarkers. Laboratory indexes with missing values over $20 \%$ were excluded, including IL-6, procalcitonin and D-dimer. Then all missing values were imputed with mean value of each laboratory index. All severe patients were randomly split into train dataset and test dataset in a ratio of 7:3. A total of 452 patients were included in train dataset, including 57 non-survivors. In this step, a decision tree classifier was developed to differentiate non-survivors from survivors. As shown in Figure 1, three biomarkers were included in the decision tree classifier, including LDH, NLR and CRP. The threshold of each biomarker helped to classify each patient into survivor group or non-survivor group. The area under the curve (AUC) of the receiver operating characteristic of this model was 0.96 , which was higher than each single biomarker (Figure 2). The associated confusion matrix of train dataset was presented in Supplementary Table 1. The accuracy of this model was 0.98 . The precision, recall and F1 score for survivor prediction was $0.97,1.00$ and 0.98 , respectively. For non-survivors, the precision, recall and F1 score was $1.00,0.81$ and 0.90 , respectively (Table 3 ).

To validate the performance of the decision tree classifier, we applied it to the test dataset. The associated confusion matrix of test dataset was presented in Supplementary Table 1. The accuracy in test dataset was also 0.98 . The precision, recall and F1 score for survivor prediction in test dataset was $0.98,0.99$ and 0.98 , respectively. For non-survivor prediction in test dataset, the precision, recall and F1 score was $0.94,0.83$ and 0.88 , respectively (Table 3 ).

\section{Discussion}

In this study, we found that COVID-19 patients in severe group or non-survivor group had a higher median age. Also, these patients had a higher proportion of comorbidities and symptoms than their counterparts. Most importantly, we proposed a machine learning model to 
quickly quantify the risk of death based on three biomarkers (LDH, NLR and CRP), which could be easily obtained on admission. This model had a high AUC of 0.96 , and performed well in both train dataset and test dataset.

Zhang and colleagues[9] reported that the median age in a small cohort of COVID-19 non-survivors was 72.5 , similar to our findings. In addition, both Zhang and we found that male COVID-19 patients accounted for the majority of the non-survivors. They also reported that approximately $76.8 \%$ of the non-survivors had comorbidities, including hypertension, heart disease, diabetes, cerebrovascular disease and cancer[9].

NLR is one of the research hotspots of inflammatory biomarkers in infectious diseases. It can comprehensively reflect the inflammatory response and immune status in patients with infectious diseases[10-12]. In COVID-19 patients, elevated NLR on admission was reported to be significantly associated with disease severity $[13,14]$. Liu and colleagues proposed a simple model based on NLR and age to stratify COVID-19 patients into four groups[15]. COVID-19 patients with age $<50$ years old and NLR $<3.13$ or NLR $\geq 3.13$ had no risk of severity, and these patients should be treated in a community hospital, home isolation or general isolation ward. While COVID-19 patients with age $\geq 50$ and NLR $<3.13$ or NLR $\geq 3.13$ had a higher risk of severity, and these patients should be admitted to isolation ward or ICU with active treatment and care. In addition, Yang and coworkers found that approximately $46.1 \%$ of the mild COVID- 19 patients could become severely ill if patients had an age $\geq 49.5$ years old and NLR $\geq 3.3[14]$. The dynamic change of NLR could also be used to distinguish severe patients from mild/moderate patients. A study demonstrated that NLR in severe group always kept a higher level on day 1, 4 and 14 compared with mild/moderate group[16]. In this study, we found that NLR $\geq 6.9$ was a high-risk factor for death in severe COVID-19 patients. In train dataset, 54 out of 113 patients with NLR $\geq 6.9$ died, while only 3 out of 339 patients with NLR $<6.9$ died. In test dataset, 18 out of 43 patients with NLR $\geq 6.9$ died, while no patients with NLR $<6.9$ died.

CRP reflects a persistent inflammatory activity state, and helps in assessing the severity of infectious patients[17]. A few studies have demonstrated that a higher CRP expression on admission was observed in severe COVID-19 patients compared with non-severe COVID19 patients[17, 18]. LDH was a biomarker of severe illness and poor prognosis in COVID-19 patients[19]. Zeng et al. found that LDH decreased within 10 days after admission in non-critical COVID-19 patients, but did not decrease obviously in critical patients or nonsurvivors[20]. These findings indicate that CRP and LDH play important roles in COVID-19 patients. In this study, LDH and CRP were also risk factors for death in severe COVID-19 patients. For LDH expression, in train dataset, 53 out of 74 patients with LDH $\geq 330$ IU/L died, while only 4 out of 378 patients with LDH $<330 \mathrm{IU} / \mathrm{L}$ died. In test dataset, 16 out of 31 patients with LDH $\geq 330 \mathrm{IU} / \mathrm{L}$ died, while only 2 out of 163 patients with LDH $<330 \mathrm{IU} / \mathrm{L}$ died. For CRP expression, in train dataset, 52 out of 126 patients with CRP $\geq 27 \mathrm{mg} / \mathrm{L}$ died, while only 5 out of 326 patients with CRP $<27 \mathrm{mg} / \mathrm{L}$ died. In test dataset, 17 out of 53 patients with $\mathrm{CRP} \geq 27 \mathrm{mg} / \mathrm{L}$ died, while only 1 out of 141 patients with $\mathrm{CRP}<27 \mathrm{mg} / \mathrm{L}$ died.

To date, a few prognostic models of COVID-19 have been developed. Dong et al. found that hypertension, higher NLR and increased NTproBNP value were significantly poorer prognostic factors in hospitalized COVID-19 patients[21]. A nomogram for predicting 14-day and 21-day probability of in-hospital survival based on the three factors was developed, with high c-index and AUC in both training and validation cohorts. Moreover, Wang et al. constructed a nomogram based on age, chest tightness, AST and BUN on admission to predict the risk of death in critical COVID-19 patients[22]. The nomogram had a sensitivity of $96.0 \%$, a specificity of $74.1 \%$ and an AUC of 0.893 .

\section{Conclusion}

In summary, this study found that male COVID-19 patients were more prone to experience severe illness and death. Clinical characteristics and laboratory examinations were significantly different between severe and non-severe groups, as well as between survivors and non-survivors. Most importantly, we identified three biomarkers (LDH, NLR and CRP) on admission as risk factors for death, and developed a simple decision tree classifier to help clinicians rapidly identify patients at high risk of death and to give priority treatment and intensive care.

\section{List Of Abbreviations}

COVID-19 - novel coronavirus disease 2019; ICU - intensive care unit;

RT-PCR - real-time reverse-transcription polymerase-chain-reaction;

IQR - interquartile range; $\quad$ WBC - white blood cell; 
NLR - neutrophil-to-lymphocyte ratio; $\quad$ CRP -- C-reactive protein;

LDH - lactic dehydrogenase; $\quad$ IL-6 - interleukin-6;

RBC - red blood cell; $\quad$ AUC - area under the curve;

\section{Declarations}

Ethics approval and consent to participate:

This study was approved by the ethics committee of the Ethics Committee of the Taikang Hospital (TKTJLL-007).

Consent for publication

Not applicable.

Availability of data and materials

The datasets used and/or analysed during the current study are available from the corresponding author on reasonable request.

Competing interests

The authors declare that they have no competing interests

Funding

None.

Authors' contributions

Contributions to the conception: Li Q, Xu Z, Wu H, Sun JG;

Design of the work: Liao TQ, Yu SY, You ZC;

The acquisition, analysis, and interpretation of data: Hou XH, Ye J, Liu G, Ma SY, Xie GF, Zhou Y, Li MX, Wu MH, Feng YM, Wang WL, Li LF, Xie DJ, Hu YH, Liu X, Wang B, Zhao ST, Li L, Luo CM, Tang T, Wu HM, Hu TY;

The preparation of figures and tables: Yang GR, Luo BY, Li LC, Yang X;

Draft the work and substantively revised it: Yang Q, Li JX, Zhang ZJ, Wu XC, Sun JG.

All authors have approved to submit this study and any substantially modified version that involves the author's contribution to the study. And all authors have agreed both to be personally accountable for the author's own contributions and to ensure that questions related to the accuracy or integrity of any part of the work, even ones in which the author was not personally involved, are appropriately investigated, resolved, and the resolution documented in the literature.

\section{Acknowledgements}

This study was supported by the Research Projects of the Joint Logistics Support Force of PLA (TKTJKY2020003, TKTJKY2020029 and TKTJKY2020136).

The authors thank all the patients for providing their clinical data.

\section{References}

[1] Wang D, Hu B, Hu C, Zhu F, Liu X, Zhang J, Wang B, Xiang H, Cheng Z, Xiong Y, Zhao Y, Li Y, Wang X, Peng Z. Clinical Characteristics of 138 Hospitalized Patients With 2019 Novel Coronavirus-Infected Pneumonia in Wuhan, China. JAMA 2020;323:1061. 
[2] Tian J, Yuan X, Xiao J, Zhong Q, Yang C, Liu B, Cai Y, Lu Z, Wang J, Wang Y, Liu S, Cheng B, Wang J, Zhang M, Wang L, Niu S, Yao Z, Deng X, Zhou F, Wei W, Li Q, Chen X, Chen W, Yang Q, Wu S, Fan J, Shu B, Hu Z, Wang S, Yang X, Liu W, Miao X, Wang Z. Clinical characteristics and risk factors associated with COVID-19 disease severity in patients with cancer in Wuhan, China: a multicentre, retrospective, cohort study. The Lancet Oncology 2020;21:893.

[3] Liang W, Liang H, Ou L, Chen B, Chen A, Li C, Li Y, Guan W, Sang L, Lu J, Xu Y, Chen G, Guo H, Guo J, Chen Z, Zhao Y, Li S, Zhang $\mathrm{N}$, Zhong N, He J. Development and Validation of a Clinical Risk Score to Predict the Occurrence of Critical Illness in Hospitalized Patients With COVID-19. JAMA INTERN MED 2020;180:1081.

[4] Huang C, Wang Y, Li X, Ren L, Zhao J, Hu Y, Zhang L, Fan G, Xu J, Gu X, Cheng Z, Yu T, Xia J, Wei Y, Wu W, Xie X, Yin W, Li H, Liu M, Xiao Y, Gao H, Guo L, Xie J, Wang G, Jiang R, Gao Z, Jin Q, Wang J, Cao B. Clinical features of patients infected with 2019 novel coronavirus in Wuhan, China. The Lancet (British edition) 2020;395:497.

[5] Wu Z, McGoogan JM. Characteristics of and Important Lessons From the Coronavirus Disease 2019 (COVID-19) Outbreak in China: Summary of a Report of 72314 Cases From the Chinese Center for Disease Control and Prevention. JAMA : the journal of the American Medical Association 2020;323:1239.

[6] Guan W, Liang W, Zhao Y, Liang H, Chen Z, Li Y, Liu X, Chen R, Tang C, Wang T, Ou C, Li L, Chen P, Sang L, Wang W, Li J, Li C, Ou L, Cheng B, Xiong S, Ni Z, Xiang J, Hu Y, Liu L, Shan H, Lei C, Peng Y, Wei L, Liu Y, Hu Y, Peng P, Wang J, Liu J, Chen Z, Li G, Zheng Z, Qiu S, Luo J, Ye C, Zhu S, Cheng L, Ye F, Li S, Zheng J, Zhang N, Zhong N, He J. Comorbidity and its impact on 1590 patients with COVID-19 in China: a nationwide analysis. EUR RESPIR J 2020;55:2000547.

[7] Zhou F, Yu T, Du R, Fan G, Liu Y, Liu Z, Xiang J, Wang Y, Song B, Gu X, Guan L, Wei Y, Li H, Wu X, Xu J, Tu S, Zhang Y, Chen H, Cao B. Clinical course and risk factors for mortality of adult inpatients with COVID-19 in Wuhan, China: a retrospective cohort study. The Lancet 2020;395:1054.

[8] National Health Commission of the People's Republic of China.

Chinese management guideline for COVID-19 (version 7.0). March 3, 2020.

http://www.nhc.gov.cn/yzygj/s7653p/202003/46c9294a7dfe4cef80dc7f5912eb1989/files/ce3e6945832a438eaae415350a8ce964.pdf (accessed March 27, 2020; in Chinese).

[9] Zhang B, Zhou X, Qiu Y, Song Y, Feng F, Feng J, Song Q, Jia Q, Wang J. Clinical characteristics of 82 cases of death from COVID-19. PLOS ONE 2020;15:e235458.

[10] Chen XQ, Xue CR, Hou P, Lin BQ, Zhang JR. Lymphocyte-to-monocyte ratio effectively predicts survival outcome of patients with obstructive colorectal cancer. World J Gastroenterol 2019;25:4970.

[11] Zhang HF, Ge YL, Wang HY, Zhang Q, Li WQ, Chen Y, Chen QC, Jin JJ, Xu J, Zhang S, Xu TT, Zhang X, Yu HL, Zhu XY, Liu CH, Bai J, Zhang JB, Xie BQ, Wang Y, Fu AS, Zhang PP. Neutrophil-to-Lymphocyte Ratio Improves the Accuracy and Sensitivity of Pneumonia Severity Index in Predicting 30-Day Mortality of CAP Patients. CLIN LAB 2019;65.

[12] Ge YL, Zhang HF, Zhang Q, Zhu XY, Liu CH, Wang N, Zhang JB, Chen H, Chen Y, Li WQ, Li ZZ, Fu AS, Wang HY. Neutrophil-toLymphocyte Ratio in Adult Community-Acquired Pneumonia Patients Correlates with Unfavorable Clinical Outcomes. CLIN LAB $2019 ; 65$.

[13] Chen R, Sang L, Jiang M, Yang Z, Jia N, Fu W, Xie J, Guan W, Liang W, Ni Z, Hu Y, Liu L, Shan H, Lei C, Peng Y, Wei L, Liu Y, Hu Y, Peng P, Wang J, Liu J, Chen Z, Li G, Zheng Z, Qiu S, Luo J, Ye C, Zhu S, Zheng J, Zhang N, Li Y, He J, Li J, Li S, Zhong N. Longitudinal hematologic and immunologic variations associated with the progression of COVID-19 patients in China. J ALLERGY CLIN IMMUN 2020;146:89.

[14] Yang AP, Liu JP, Tao WQ, Li HM. The diagnostic and predictive role of NLR, d-NLR and PLR in COVID-19 patients. INT IMMUNOPHARMACOL 2020;84:106504.

[15] Liu J, Liu Y, Xiang P, Pu L, Xiong H, Li C, Zhang M, Tan J, Xu Y, Song R, Song M, Wang L, Zhang W, Han B, Yang L, Wang X, Zhou G, Zhang T, Li B, Wang Y, Chen Z, Wang X. Neutrophil-to-lymphocyte ratio predicts critical illness patients with 2019 coronavirus disease in the early stage. J TRANSL MED 2020;18:206.

Page 7/12 
[16] Fu J, Kong J, Wang W, Wu M, Yao L, Wang Z, Jin J, Wu D, Yu X. The clinical implication of dynamic neutrophil to lymphocyte ratio and D-dimer in COVID-19: A retrospective study in Suzhou China. THROMB RES 2020;192:3.

[17] Danwang C, Endomba FT, Nkeck JR, Wouna D, Robert A, Noubiap JJ. A meta-analysis of potential biomarkers associated with severity of coronavirus disease 2019 (COVID-19). Biomark Res 2020;8:37.

[18] Zhang JJ, Dong X, Cao YY, Yuan YD, Yang YB, Yan YQ, Akdis CA, Gao YD. Clinical characteristics of 140 patients infected with SARS-CoV-2 in Wuhan, China. ALLERGY 2020;75:1730.

[19] Ke C, Yu C, Yue D, Zeng X, Hu Z, Yang C. Clinical Characteristics of confirmed and clinically diagnosed patients with 2019 novel coronavirus pneumonia: a single-center, retrospective, case-control study. Med Clin (Barc) 2020.

[20] Zeng Z, Yu H, Chen H, Qi W, Chen L, Chen G, Yan W, Chen T, Ning Q, Han M, Wu D. Longitudinal changes of inflammatory parameters and their correlation with disease severity and outcomes in patients with COVID-19 from Wuhan, China. CRIT CARE 2020;24:525.

[21] Dong YM, Sun J, Li YX, Chen Q, Liu QQ, Sun Z, Pang R, Chen F, Xu BY, Manyande A, Clark TG, Li JP, Orhan IE, Tian YK, Wang T, Wu W, Ye DW. Development and Validation of a Nomogram for Assessing Survival in Patients with COVID-19 Pneumonia. CLIN INFECT DIS 2020.

[22] Wang B, Zhong F, Zhang H, An W, Liao M, Cao Y. Risk factors analysis and nomogram construction of non-survivors in critical patients with COVID-19. JPN J INFECT DIS 2020.

\section{Tables}

Table 1: Demographics, clinical characteristics and laboratory findings of severe COVID-19 patients and non-severe COVID-19 patients 


\begin{tabular}{|c|c|c|c|c|}
\hline Variables & Total $(\mathrm{N}=2169)$ & Severe $(\mathrm{N}=646)$ & Non-severe $(\mathrm{N}=1523)$ & $P$ value ${ }^{a}$ \\
\hline Age, years old & $61(50,70)$ & $68(60,76)$ & $58(47,66)$ & $<0.001$ \\
\hline Sex & & & & $<0.001$ \\
\hline Male & $1036(48)$ & $360(56)$ & $676(44)$ & \\
\hline Female & $1133(52)$ & $286(44)$ & $847(56)$ & \\
\hline Smoking history & & & & 0.582 \\
\hline Never & $1985(92)$ & $587(91)$ & $1398(92)$ & \\
\hline Former & $80(4)$ & $28(4)$ & $52(3)$ & \\
\hline Current & $104(4)$ & $31(5)$ & $73(5)$ & \\
\hline Body temperature & & & & $<0.001$ \\
\hline$<37.3{ }^{\circ} \mathrm{C}$ & $2052(95)$ & $589(91)$ & $1463(96)$ & \\
\hline $37.3-38.0^{\circ} \mathrm{C}$ & $87(4)$ & $37(6)$ & $50(3)$ & \\
\hline$>38.0^{\circ} \mathrm{C}$ & $30(1)$ & $20(3)$ & $10(1)$ & \\
\hline Oxygen saturation & & & & $<0.001$ \\
\hline$\leq 93 \%$ & $270(12)$ & $270(42)$ & $0(0)$ & \\
\hline$>93 \%$ & $1899(88)$ & $376(58)$ & $1523(100)$ & \\
\hline Heart rate & & & & 0.009 \\
\hline Normal & $1810(83)$ & $518(80)$ & $1292(85)$ & \\
\hline Abnormal & $359(17)$ & $128(20)$ & $231(15)$ & \\
\hline Respiratory rate & & & & $<0.001$ \\
\hline$\leq 20$ per minute & $1573(73)$ & $343(53)$ & $1230(81)$ & \\
\hline $21-29$ per minute & $528(24)$ & $235(36)$ & $293(19)$ & \\
\hline$\geq 30$ per minute & $68(3)$ & $68(11)$ & $0(0)$ & \\
\hline No. of comorbidities & & & & $<0.001$ \\
\hline 0 & $1035(48)$ & $196(30)$ & $839(55)$ & \\
\hline 1 & $591(27)$ & $186(29)$ & $405(27)$ & \\
\hline$\geq 2$ & $543(25)$ & $264(41)$ & $279(18)$ & \\
\hline No. of systems symptoms & & & & $<0.001$ \\
\hline 0 & $93(4)$ & $12(2)$ & $81(5)$ & \\
\hline 1 & $728(34)$ & $164(25)$ & $564(37)$ & \\
\hline 2 & $1130(52)$ & $386(60)$ & 744 (49) & \\
\hline$\geq 3$ & $218(10)$ & $84(13)$ & $134(9)$ & \\
\hline White blood cell count, $\times 10^{9} / \mathrm{L}$ & $5.8(4.74,7.06)$ & $6.23(4.98,8)$ & $5.68(4.69,6.83)$ & $<0.001$ \\
\hline Neutrophil count, $\times 10^{9} / \mathrm{L}$ & $3.48(2.62,4.59)$ & $4.02(3,5.93)$ & $3.28(2.52,4.25)$ & $<0.001$ \\
\hline Lymphocyte count, $\times 10^{9} / \mathrm{L}$ & $1.53(1.13,1.91)$ & $1.2(0.8,1.69)$ & $1.63(1.27,1.97)$ & $<0.001$ \\
\hline Neutrophil-to-lymphocyte ratio & $2.23(1.62,3.31)$ & $3.21(1.99,6.62)$ & $2.03(1.5,2.77)$ & $<0.001$ \\
\hline Monocyte count, $\times 10^{9} / \mathrm{L}$ & $0.47(0.37,0.59)$ & $0.48(0.36,0.62) ; \mathrm{n}=646$ & $0.47(0.38,0.59) ; \mathrm{n}=1516$ & 0.906 \\
\hline Eosinophilia count, $\times 10^{9} / \mathrm{L}$ & $0.11(0.06,0.18)$ & $0.09(0.03,0.17) ; \mathrm{n}=646$ & $0.11(0.07,0.18) ; \mathrm{n}=1516$ & $<0.001$ \\
\hline Basophilia count, $\times 10^{9} / \mathrm{L}$ & $0.03(0.01,0.04)$ & $0.02(0.01,0.03) ; \mathrm{n}=646$ & $0.03(0.02,0.04) ; \mathrm{n}=1517$ & $<0.001$ \\
\hline Red blood cell count, $\times 10^{9} / \mathrm{L}$ & $4.02(3.63,4.4)$ & $3.85(3.44,4.24) ; \mathrm{n}=644$ & $4.08(3.72,4.46) ; n=1513$ & $<0.001$ \\
\hline Hemoglobin, $\mathrm{g} / \mathrm{L}$ & $121(110,133)$ & $117(102,128) ; \mathrm{n}=644$ & $123(113,134) ; \mathrm{n}=1514$ & $<0.001$ \\
\hline Platelet count, $\times 10 \square / \mathrm{L}$ & $221.5(180,272)$ & $216(164,275) ; \mathrm{n}=645$ & $224(185,270) ; n=1519$ & 0.008 \\
\hline C-reactive protein, $\mathrm{mg} / \mathrm{L}$ & $1.32(0.5,7.35)$ & $6.38(1,32.14) ; \mathrm{n}=638$ & $0.77(0.5,3.36) ; \mathrm{n}=1438$ & $<0.001$ \\
\hline Lactic dehydrogenase, IU/L & $176.92(149.9,216.95)$ & $212(172.2,279.36) ; \mathrm{n}=625$ & $166.92(144.97,197.7) ; \mathrm{n}=1437$ & $<0.001$ \\
\hline Interleukin-6, $\mathrm{pg} / \mathrm{mL}$ & $2.48(1.5,6.36)$ & $6.84(2.73,21.23) ; \mathrm{n}=404$ & $1.77(1.5,3.68) ; \mathrm{n}=961$ & $<0.001$ \\
\hline Procalcitonin, ng/mL & $0.05(0.03,0.08)$ & $0.07(0.04,0.14) ; \mathrm{n}=514$ & $0.04(0.03,0.06) ; \mathrm{n}=947$ & $<0.001$ \\
\hline D-dimer, $\mu \mathrm{g} / \mathrm{mL}$ & $0.39(0.18,0.8)$ & $0.64(0.31,1.49) ; \mathrm{n}=420$ & $0.3(0.14,0.55) ; \mathrm{n}=701$ & $<0.001$ \\
\hline
\end{tabular}

Data are $\mathrm{n}(\%), \mathrm{n} / \mathrm{N}(\%)$, or median (IQR), unless specified otherwise. Temperature, oxygen saturation, heart rate, respiratory rate were detected at rest when patients were admitted to hospital.

${ }^{\text {a }} P$ values indicate differences between severe and non-severe patients.

Table 2: Demographics, clinical characteristics and laboratory findings of survivors and non-survivors 


\begin{tabular}{|c|c|c|c|}
\hline Variables & Non-survivor $(\mathrm{N}=75)$ & Survivor $(\mathrm{N}=2094)$ & $P$ value $^{a}$ \\
\hline Age, years old & $72(67,82)$ & $61(50,69)$ & $<0.001$ \\
\hline Sex & & & 0.003 \\
\hline Male & $49(65)$ & $987(47)$ & \\
\hline Female & $26(35)$ & $1107(53)$ & \\
\hline Smoking history & & & 0.325 \\
\hline Never & 66 (88) & 1919 (92) & \\
\hline Former & $3(4)$ & $77(4)$ & \\
\hline Current & $6(8)$ & $98(5)$ & \\
\hline Body temperature & & & $<0.001$ \\
\hline$<37.3^{\circ} \mathrm{C}$ & $54(72)$ & $1998(95)$ & \\
\hline $37.3-38.0^{\circ} \mathrm{C}$ & $12(16)$ & $75(4)$ & \\
\hline$>38.0^{\circ} \mathrm{C}$ & $9(12)$ & $21(1)$ & \\
\hline Oxygen saturation & & & $<0.001$ \\
\hline$\leq 93 \%$ & $59(79)$ & $211(10)$ & \\
\hline$>93 \%$ & $16(21)$ & $1883(90)$ & \\
\hline Heart rate & & & $<0.001$ \\
\hline Normal & $51(68)$ & $1759(84)$ & \\
\hline Abnormal & $24(32)$ & $335(16)$ & \\
\hline Respiratory rate & & & $<0.001$ \\
\hline$\leq 20$ per minute & $26(35)$ & $1547(74)$ & \\
\hline 21-29 per minute & 35 (47) & $493(24)$ & \\
\hline$\geq 30$ per minute & $14(19)$ & $54(3)$ & \\
\hline No. of comorbidities & & & $<0.001$ \\
\hline 0 & $11(15)$ & $1024(49)$ & \\
\hline 1 & $17(23)$ & $574(27)$ & \\
\hline$\geq 2$ & $47(63)$ & $496(24)$ & \\
\hline No. of systems symptoms & & & 0.03 \\
\hline 0 & $3(4)$ & $90(4)$ & \\
\hline 1 & $14(19)$ & $714(34)$ & \\
\hline 2 & $49(65)$ & $1081(52)$ & \\
\hline$\geq 3$ & $9(12)$ & $209(10)$ & \\
\hline White blood cell count, $\times 10^{9} / \mathrm{L}$ & $10.2(7.27,14.09)$ & $5.75(4.71,6.94)$ & $<0.001$ \\
\hline Neutrophil count, $\times 10^{9} / \mathrm{L}$ & $9.62(6.8,13.53)$ & $3.42(2.59,4.46)$ & $<0.001$ \\
\hline Lymphocyte count, $\times 10^{9} / \mathrm{L}$ & $0.56(0.4,0.8)$ & $1.56(1.17,1.92)$ & $<0.001$ \\
\hline Neutrophil-to-lymphocyte ratio & $16.98(11.88,26.16)$ & $2.18(1.6,3.15)$ & $<0.001$ \\
\hline Monocyte count, $\times 10^{9} / \mathrm{L}$ & $0.38(0.22,0.64) ; \mathrm{n}=75$ & $0.48(0.38,0.59) ; \mathrm{n}=2087$ & 0.002 \\
\hline Eosinophilia count, $\times 10^{9} / \mathrm{L}$ & $0.01(0,0.04) ; \mathrm{n}=75$ & $0.11(0.06,0.18) ; \mathrm{n}=2087$ & $<0.001$ \\
\hline Basophilia count, $\times 10^{9} / \mathrm{L}$ & $0.01(0,0.02) ; \mathrm{n}=75$ & $0.03(0.02,0.04) ; \mathrm{n}=2088$ & $<0.001$ \\
\hline Red blood cell count, $\times 10^{9} / \mathrm{L}$ & $4.02(3.31,4.34) ; \mathrm{n}=75$ & $4.02(3.64,4.4) ; \mathrm{n}=2083$ & 0.051 \\
\hline Hemoglobin, $\mathrm{g} / \mathrm{L}$ & $118(101,134) ; n=75$ & $121(110,132) ; \mathrm{n}=2083$ & 0.213 \\
\hline Platelet count, $\times 10 \mathrm{a} / \mathrm{L}$ & $172(89,263) ; n=75$ & $223(182,273) ; n=2089$ & $<0.001$ \\
\hline C-reactive protein, $\mathrm{mg} / \mathrm{L}$ & $89.33(38.26,135.91) ; n=75$ & $1.18(0.5,6.09) ; \mathrm{n}=2001$ & $<0.001$ \\
\hline Lactic dehydrogenase, IU/L & $429.14(366,541.2) ; n=73$ & $175.2(148.9,211.2) ; \mathrm{n}=1989$ & $<0.001$ \\
\hline Interleukin-6, $\mathrm{pg} / \mathrm{mL}$ & $65.28(20.41,154.1) ; \mathrm{n}=27$ & $2.42(1.5,5.91) ; \mathrm{n}=1338$ & $<0.001$ \\
\hline Procalcitonin, ng/mL & $0.28(0.14,0.66) ; \mathrm{n}=63$ & $0.04(0.03,0.08) ; \mathrm{n}=1398$ & $<0.001$ \\
\hline D-dimer, $\mu \mathrm{g} / \mathrm{mL}$ & $2.43(0.78,5.61) ; \mathrm{n}=47$ & $0.37(0.17,0.74) ; \mathrm{n}=1074$ & $<0.001$ \\
\hline
\end{tabular}

Data are $\mathrm{n}(\%), \mathrm{n} / \mathrm{N}(\%)$, or median (IQR), unless specified otherwise. Temperature, oxygen saturation, heart rate, respiratory rate were detected at rest when patients were admitted to hospital.

${ }^{\mathrm{a}} P$ values indicate differences between survivors and non-survivors.

Table 3: Performance of the decision tree classifier on the train and test datasets

\begin{tabular}{lcccc}
\hline Train dataset & Precision & Recall & F1 score & Support \\
\hline Survivor & 0.97 & 1.00 & 0.98 & 406 \\
Non-survivor & 1.00 & 0.81 & 0.90 & 46 \\
Accuracy & & & 0.98 & 452 \\
\hline Test dataset & Precision & Recall & F1 score & Support \\
\hline Survivor & 0.98 & 0.99 & 0.98 & 178 \\
Non-survivor & 0.94 & 0.83 & 0.88 & 16 \\
Accuracy & & & 0.98 & 452 \\
\hline
\end{tabular}




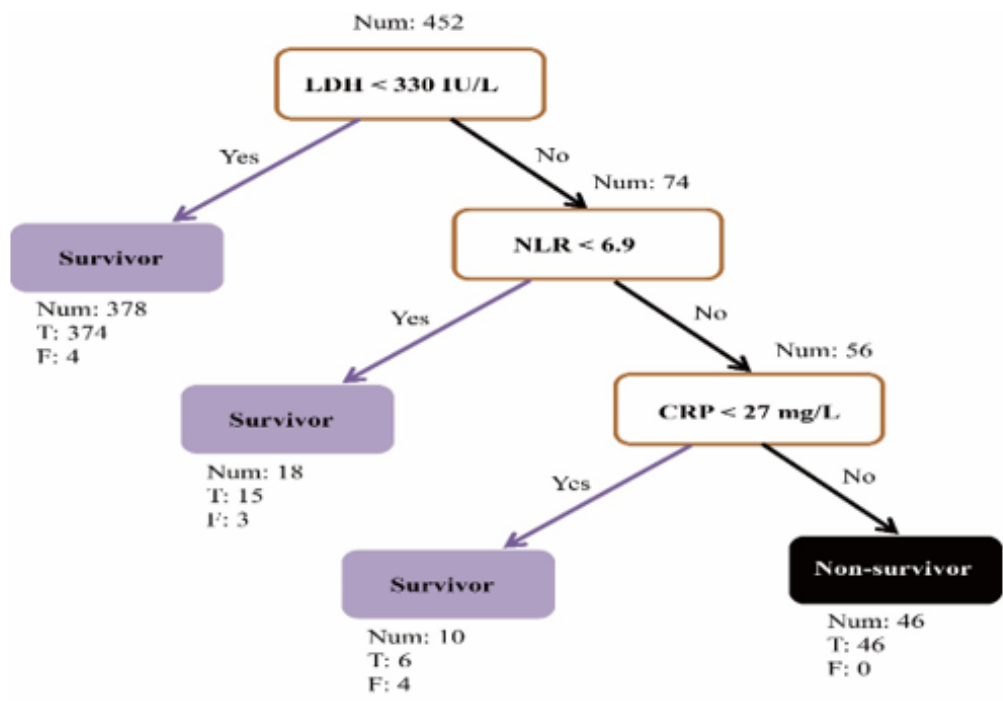

\section{Figure 1}

A decision tree classifier using three biomarkers and their thresholds in absolute value to predict death outcome in severe COVID-19 patients. Num, the number of patients in a class; $T$, the number of correctly classified patients; $F$, the number of misclassified patients; NLR, neutrophil-to-lymphocyte ratio; CRP, C-reactive protein; LDH, lactic dehydrogenase; COVID-19, novel coronavirus disease 2019.
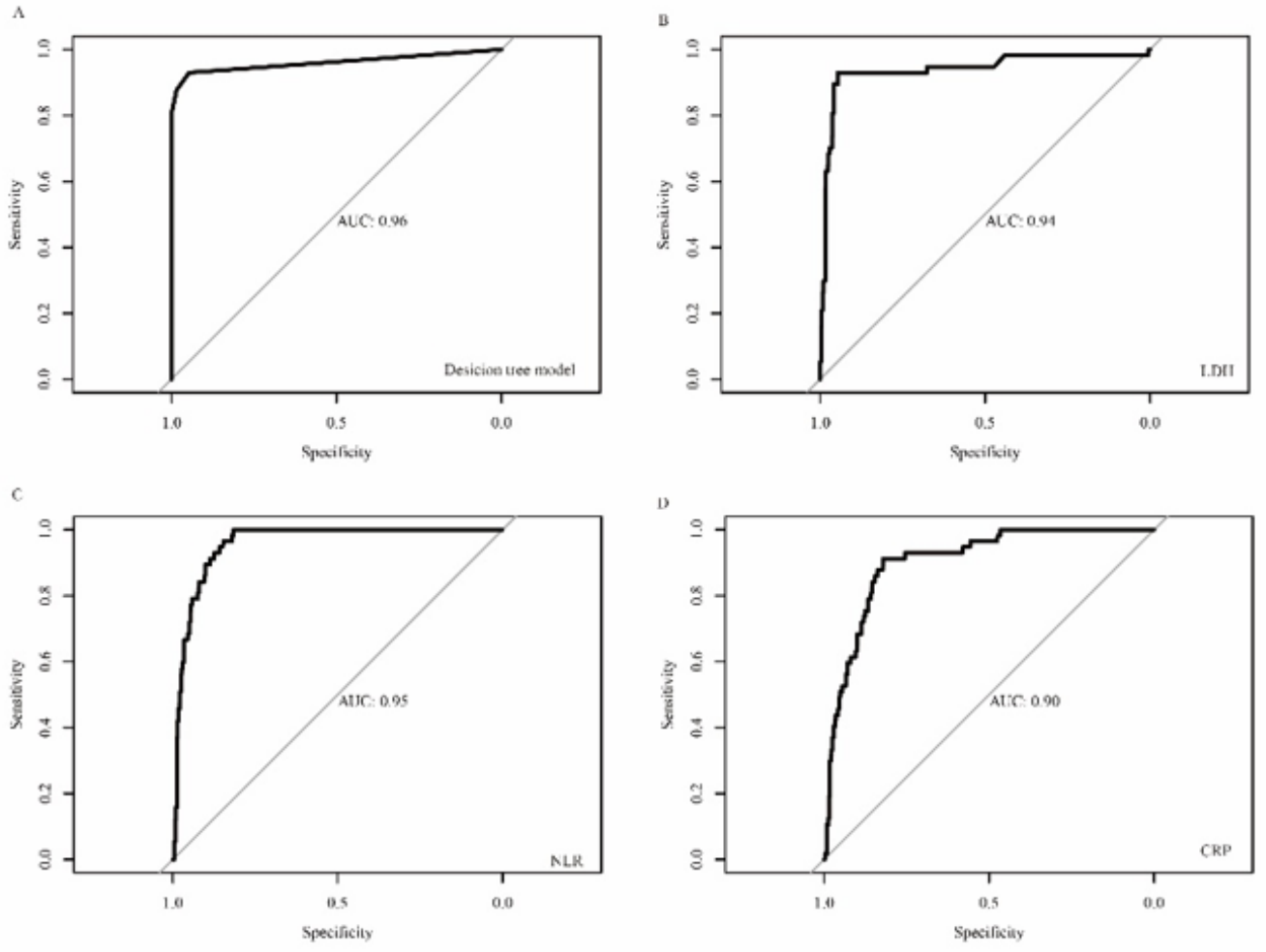

\section{Figure 2}

ROC curves for the decision tree classifier and each biomarker. (A) ROC curve for the decision tree classifier; (B) ROC curve for LDH; (C) ROC curve for NLR; (D) ROC curve for CRP. ROC, receiver operating characteristic; NLR, neutrophil-to-lymphocyte ratio; CRP, C-reactive protein; LDH, lactic dehydrogenase; AUC, area under the curve of ROC.

\section{Supplementary Files}

This is a list of supplementary files associated with this preprint. Click to download. 
- SupplementaryTable1.docx

Page $12 / 12$ 